\title{
PI3-kinase/Akt Pathway Mediates Expression of p53 after UVB Irradiation
}

\author{
Yuko Ibuki ${ }^{1}$, Marie Akaike and Tatsushi Toyooka \\ Graduate School of Nutritional and Environmental Sciences, University of Shizuoka, Shizuoka, Japan
}

(Received September 21, 2010; Revised October 25, 2010; Accepted October 26, 2010)

The cells having unrepaired DNA damage after ultraviolet (UV) exposure must go to apoptotic cell death to avoid mutation and transformation leading to cancer, whereas they must be protected against excess apoptotic cell death. The phosphatidylinositol 3-kinase (PI3-kinase)/Akt is a well-known survival pathway which suppresses apoptosis. The p53 tumor suppressor is a universal sensor of genotoxic stress that also regulates apoptosis. Until now, there are many reports of p53 expression after UV irradiation; however, the detailed time-course study has not been performed, especially the relationship with PI3-kinase/Akt pathway. In this study, PI3-kinase/Akt pathway-mediated time-dependent expressions of p53 and its related molecules after UVB irradiation were examined involving induction of apoptosis. Inhibition of PI3-kinase/Akt pathway by wortmannin and siRNA for Akt1 augmented apoptosis induced by UVB irradiation. p53 was time-dependently phosphorylated and stabilized after UVB irradiation, consistent with the expression of p21. Inhibition of PI3kinase/Akt pathway clearly suppressed the expressions of p53 and p21. On the other hand, the expression levels of p53 in the presence of proteasome inhibitor were same, whether PI3-kinase/Akt pathway was inhibited or not, indicating that the activation of PI3-kinase/Akt pathway after UVB exposure suppressed proteasome-dependent degradation of p53. These results suggested that PI3kinase/Akt pathway has important roles to mediate p53 expression and induction of apoptosis after UVB irradiation although the p53 revealed no positive correlation with the induction of apoptosis.

Key words: Akt, p53, UVB, apoptosis

\section{Introduction}

Ultraviolet (UV) radiation from the sun is among ubiquitous damaging environmental factors from which human skin must protect itself. The UV spectrum can be divided into three based on wavelength-UVA (320-400 $\mathrm{nm})$, UVB $(280-320 \mathrm{~nm})$, and UVC (200-280 $\mathrm{nm})$. As UVC could not reach to surface of the earth due to the effective absorbance in the stratospheric ozone layer, UVB directly absorbed by DNA mainly accounts for damaging biological effect of UV irradiation leading to skin cancer.

UVB-induced DNA damage is usually repaired through nucleotide excision repair (NER) system; however, with increasing the damage, NER will ultimately fail and replication of damaged DNA leads to an error-prone incorporation of nucleotides at the site of a photolesion, increasing the risk of malignant transformation. To avoid this process, cells possess a fail-safe mechanism. This is the formation of sunburn cells, which is undergoing apoptosis in skin keratinocytes. This means that disregulation of the apoptosis is a factor of development of skin cancer (1).

In apoptosis, p53 tumor suppressor is considered to be a key protein (2). p53 mutation and deletion attenuate apoptosis of abnormal cells and permit undesirable cell proliferation, leading to cancer. The critical role of p53 in the prevention of cancer development is demonstrated by p 53 mutation in approximately $50 \%$ of human cancer cases. The action of p53 in the case of UVexposure has been well examined. In response to UVB radiation, p53 is phosphorylated by MAP kinases, ERKs and p38 (3). Ziegler et al. (4) showed a reduction of sunburn cells in the skin of $p 53^{-/-}$mice, indicating that the process whereby precancerous keratinocytes are eliminated may not work well in cells that harbor p53 inactivated by mutations. This was followed with the report by Jiang et al. (5) that UVB-induced skin tumors develop more in $p 53^{-/-}$and $p 53^{+/-}$mice than in the wild type mice. Activation of $\mathrm{p} 53$ by polyphenolic flavonoid enhanced UVB-induced apoptosis (6). Although some studies supported a contribution of p53 to the promotion of UV-induced apoptosis as described above, several studies have claimed that UV-induced apoptosis is not necessarily mediated by p53. Knockdown of p53 and inhibition of the activity enhanced UV-inducing apoptosis (7-9). Ikehata et al. (10) showed that p53 protected UVB-induced genotoxicity by facilitating NER

${ }^{1}$ Correspondenc to: Yuko Ibuki, Graduate School of Nutritional and Environmental Sciences, University of Shizuoka, 52-1 Yada, Shizuoka 422-8526, Japan. Tel/Fax: +81-54-264-5799, E-mail: ibuki@ushizuoka-ken. ac.jp 
and that its contribution to the UVB-induced apoptosis was limited. At present, the contribution of p53 to apoptosis induction in the response to UV-induced damage is controversial.

Several signal pathways activated by UV irradiation have been reported, in which phosphatidylinositol 3kinase (PI3-kinase)/Akt is a noted survival pathway $(11,12)$. Exposure to UVB induces clustering and internalization of cell surface receptors like epidermal growth factor (EGF) receptor (13), resulting in activation of the enzyme PI3-kinase leading to the formation of 3-phosphorylated phosphatidylinositols, which in turn activate the serine/threonine kinase Akt/PKB (11). Akt promotes cell survival by phosphorylating the Bcl-2 family member Bad (14) and activation of mitochondrial Raf-1 (15). Many studies have reported that UVB-induced apoptosis could be suppressed by treatment with insulin-like growth factor (IGF), demonstrating that the PI3-kinase/Akt pathway was essential for protecting cells against UV-induced apoptosis (16-19). We have previously shown that UVB irradiation inhibited apoptotic cell death induced by cell detachment and serum starvation (anoikis), which was mediated by activation of PI3-kinase/Akt pathway (20). On the other hand, the relationship between activation of the PI3-kinase/Akt pathway and p53 expression after UV irradiation has not been well investigated. A few reports have shown that the activation of the PI3-kinase/Akt pathway by exposure to UVB was observed in keratinocytes both in vivo and in vitro, which might erase the excess production of sunburn cells in the skin, indicating an enhancement of the survival of mutated cells leading to the promotion of skin cancer $(11,12)$. If p53 contributes to induction of sunburn cells after UVB irradiation, PI3kinase/Akt pathway might mediate the expression of p53 by UVB irradiation. Boehme et al. (21) reported that Akt stabilized p53 in response to DNA damage by ionizing radiation. However, time-dependent Aktmediated changes of expression of p53 after UV irradiation have not yet been clarified.

In this study, time-dependent p53 expression after UVB irradiation and contribution of PI3-kinase/Akt pathway were examined involving induction of apoptosis. PI3-kinase inhibitors, wortmannin and LY294002, and knockdown method using siRNA for Akt1 were applied for inhibition of PI3-kinase/Akt pathway.

\section{Materials and Methods}

Cell culture and siRNA transfection: NIH3T3 cells were used for experiments because of its reproducibility of knockdown efficiency for Akt1. They were cultured with Dulbecco's modified Eagle medium (DMEM) supplemented with $10 \%$ calf serum (CS) at $37^{\circ} \mathrm{C}$ in a humidified atmosphere containing $5 \% \mathrm{CO}_{2}$ in air. For the siRNA experiments, the cells were seeded at $3 \times 10^{6}$ cells $/ 100 \mathrm{~mm}$ tissue culture dish. Control non-targeting siRNA (control siRNA) was purchased from Dharmacon, Inc. (Chicago, IL.). Akt1 siRNA was synthesized using the sequence which showed the most effective gene silencing of the four Akt1 siRNA which were in the duplex oligonucleotide cocktail purchased from Dharmacon, Inc. (20). After $24 \mathrm{~h}$ of culture, the cells were transfected with $1.2 \mathrm{nmol}$ of annealed siRNA per 100 $\mathrm{mm}$ dish using Lipofectamine 2000 (Invitrogen, Co., Carlsbad, CA) as recommended by the manufacturer. Following further culture for $48 \mathrm{~h}$, the cells were plated in 24 well plates or $35 \mathrm{~mm}$ dish for experiments and cultured for $24 \mathrm{~h}$.

UVB irradiation: After culture for $3 \mathrm{~h}$ in serum-free DMEM, cells were irradiated with UVB. The wavelength characteristics of the UVB lamp (HP-30LM; Atto, Co., Tokyo, Japan) with a $280-320 \mathrm{~nm}$ emission and a max peak of $312 \mathrm{~nm}$ were as described in the previous paper (22). The approximate irradiance of UVB at the sample level was $0.8 \mathrm{~mW} / \mathrm{cm}^{2}$. The duration of UVB irradiation to obtain a dose of $0.1 \mathrm{~J} / \mathrm{cm}^{2}$ was about $2.5 \mathrm{~min}$.

Viability assay: UVB-irradiated cells were cultured for $48 \mathrm{~h}$ and trypsinized to obtain single cell suspension. They were incubated in DMEM containing fluorescein diacetate (FDA) $(0.1 \mu \mathrm{g} / \mathrm{ml})$ for $10 \mathrm{~min}$ at $37^{\circ} \mathrm{C}$, and viability was determined using a flowcytometer (FCM) (Epics XL; Beckman Coulter, Inc., Hialeah, FL).

Determination of apoptotic cells: Apoptosis was examined by detecting chromatin-condensed cells. UVB-irradiated cells were stained with the DNA-binding fluorochrome Hoechst 33342 as described previously (22). Briefly, trypsinized cells were fixed in $2 \%$ glutaraldehyde for $4 \mathrm{~h}$, and then suspended in PBS containing 1 $\mathrm{mM}$ Hoechst33342. Following incubation for $10 \mathrm{~min}$ at room temperature, chromatin-condensed cells were scored microscopically.

Western blotting: Cells were lysed in lysis sample buffer $(50 \mathrm{mM}$ Tris-HCl, pH 8.0, $5 \mathrm{mM}$ EDTA, 150 $\mathrm{mM} \mathrm{NaCl}, 0.5 \%$ Nonidet P-40, and $1 \mathrm{mM}$ PMSF). When cell fractionation was needed, cells were lysed in buffer $(10 \mathrm{mM}$ Hepes-KOH, pH 7.8, $10 \mathrm{mM} \mathrm{KCl,} 0.1$ mM EDTA, $0.1 \%$ Nonidet P-40, and $1 \mathrm{mM}$ PMSF) and centrifuged at $12000 \mathrm{rpm}$ for $5 \mathrm{~min}$ (supernatant: cytoplasm fraction). The precipitation was lysed in lysis sample buffer (nucleus fraction). The lysates were separated by SDS-PAGE followed by electroblotting onto PVDF membranes (Immobilon-P; Millipore Co., Bedford, MA). After the blocking of nonspecific binding with $1 \%$ skim milk, the membranes were incubated with primary antibody followed by horseradish peroxidaseconjugated secondary antibody (Jackson Immunoresearch Lab., Inc., West Grove, PA). The primary antibodies against p53 (Oncogene Research Product), p21, Bcl-2, Bax, Actin (Santa Cruz Biotech. Inc., Santa 
Cruz, CA) and Akt1 (Sigma-Aldrich Co., St. Louis, MO) were diluted 1:1000 to 1:8000 for use and secondary antibodies were diluted 1:2500. Signals were detected with the ECL chemiluminescence detection system (GE Healthcare Bio-Sciences, Co., Piscataway, $\mathrm{NJ}$ ). Brightness of protein bands was calculated using NIH-image (version 1.61).

Statistics: All experiments were repeated two or three times. ANOVA was used to test the significance between groups $(n=3 \sim 5)$. $P$ values $<0.05$ were considered statistically significant.

\section{Results}

Akt1 knockdown enhances UVB-induced cell death: Figure 1A shows Akt1 expression $48 \mathrm{~h}$ after transfection of siRNA. The expression decreased below $30 \%$ of control. UVB exposure induced dose-dependent cell death, which was enhanced by the Akt1 knockdown (Fig. 1B). The enhanced cell death was apoptosis because typical apoptotic marker, chromatin condensation increased in Akt1-knockdown cells (Fig. 1C). Treatment with PI3-kinase inhibitor, wortmannin also increased the chromatin condensation after UVB irradiation (Fig. 1D).
Inhibition of PI3-kinase/Akt pathway suppresses expressions of $p 53$ and $p 21$ after UVB exposure: Figure 2A shows the expression changes of p53, p21 and Bcl-2 family proteins after UVB exposure. After UVB exposure $\left(0.05 \mathrm{~J} / \mathrm{cm}^{2}\right)$, expression of p53 and phosphorylated p53 (upper bands) increased up to $8 \mathrm{~h}$, then gradually decreased to $24 \mathrm{~h}$. The pattern was different from the case of $0.1 \mathrm{~J} / \mathrm{cm}^{2}$ of UVB exposure, in which p53 expression continuously increased up to $24 \mathrm{~h}$. The expression patterns determined using image analyzer are shown in Fig. 3A. Akt1 knockdown attenuated the increase of p53 expression. PI3-kinase inhibitors, wortmannin and LY294002, also suppressed the increase of p53 expression (Figs. 2B and C). Behavior of p21 was consistent with p53 (Figs. 2 and 3B). On the other hand, the expressions of Bcl-2 family, Bcl-2 and Bax were not much changed by UVB irradiation comparing with $\mathrm{p} 53$ and $\mathrm{p} 21$. Slight decrease of Bcl-2 was observed 16 to 24 $\mathrm{h}$ after UVB irradiation only in the condition of Akt1 knockdown.

Localization of p53 and its stabilization via PI3kinase/Akt pathway: To clarify where the accumulation of p53 was caused and attenuated by inhibition of PI3-kinase/Akt pathway, the cells irradiated with UVB
A

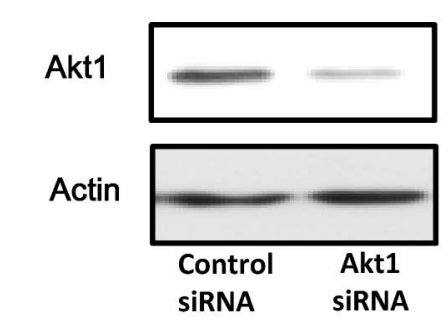

C

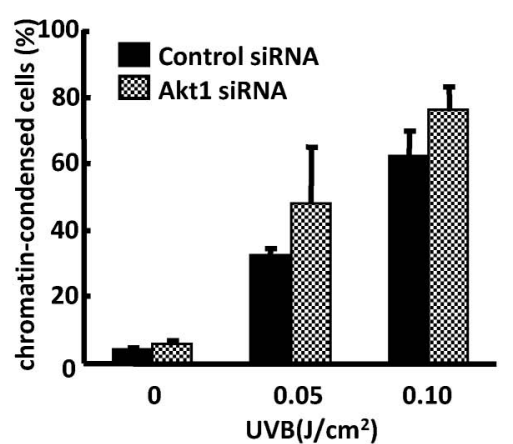

B

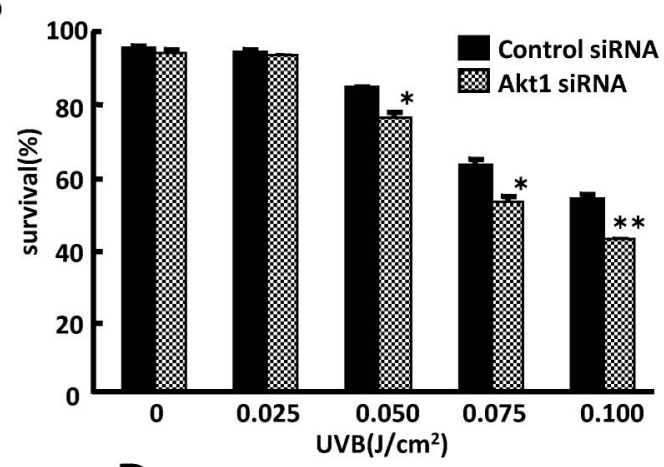

D

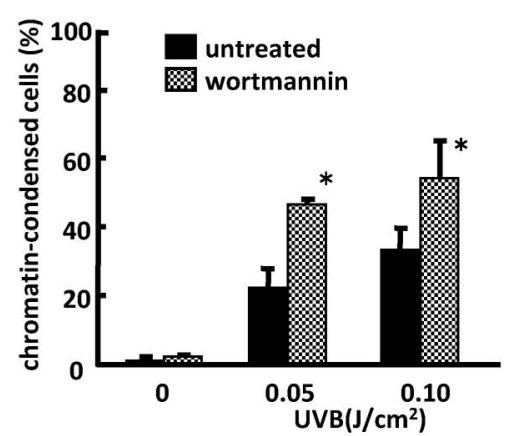

Fig. 1 Akt1 knockdown and apoptosis induction after UVB exposure. (A) Nontargeting siRNA and Akt1 siRNA (1.2 nmol) were transfected into NIH3T3 cells $\left(3 \times 10^{6}\right.$ cells $/ 100 \mathrm{~mm}$ dish) and cultured for $48 \mathrm{~h}$. Akt 1 protein expression was analyzed by western blotting. (B) Survival $48 \mathrm{~h}$ after UVB exposure was determined by FDA assay. Akt1-knocked down cells (C) or cells treated with $100 \mathrm{nM}$ wortmannin for $1 \mathrm{~h}$ (D) were irradiated with UVB and further cultured for $48 \mathrm{~h}$. The cells were stained by Hoechst 33342 and chromatin-condensed cells were scored microscopically. Values are means \pm SD. ${ }^{*} P<0.05$. 

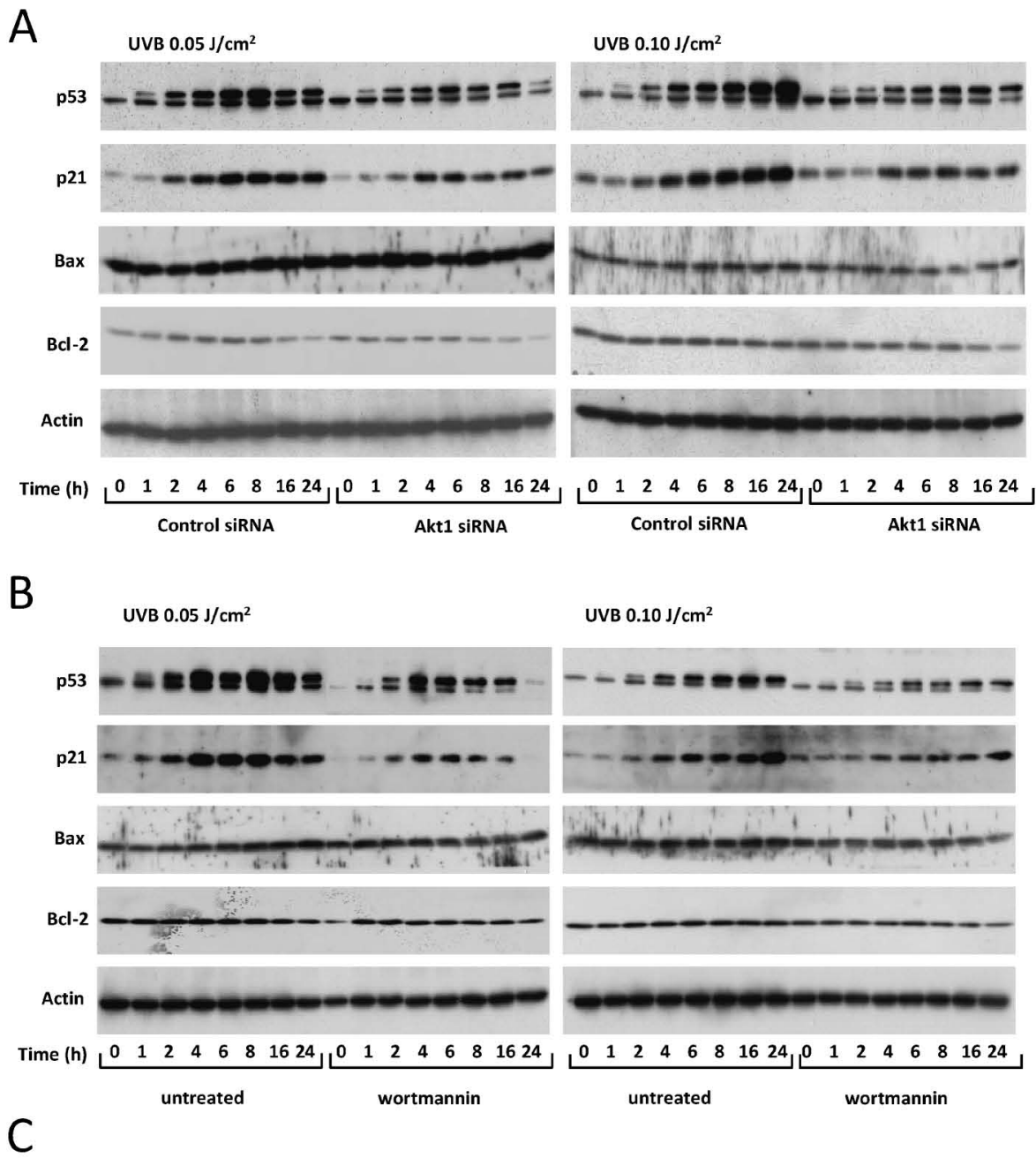

$$
\text { UVB } 0.10 \mathrm{~J} / \mathrm{cm}^{2}
$$
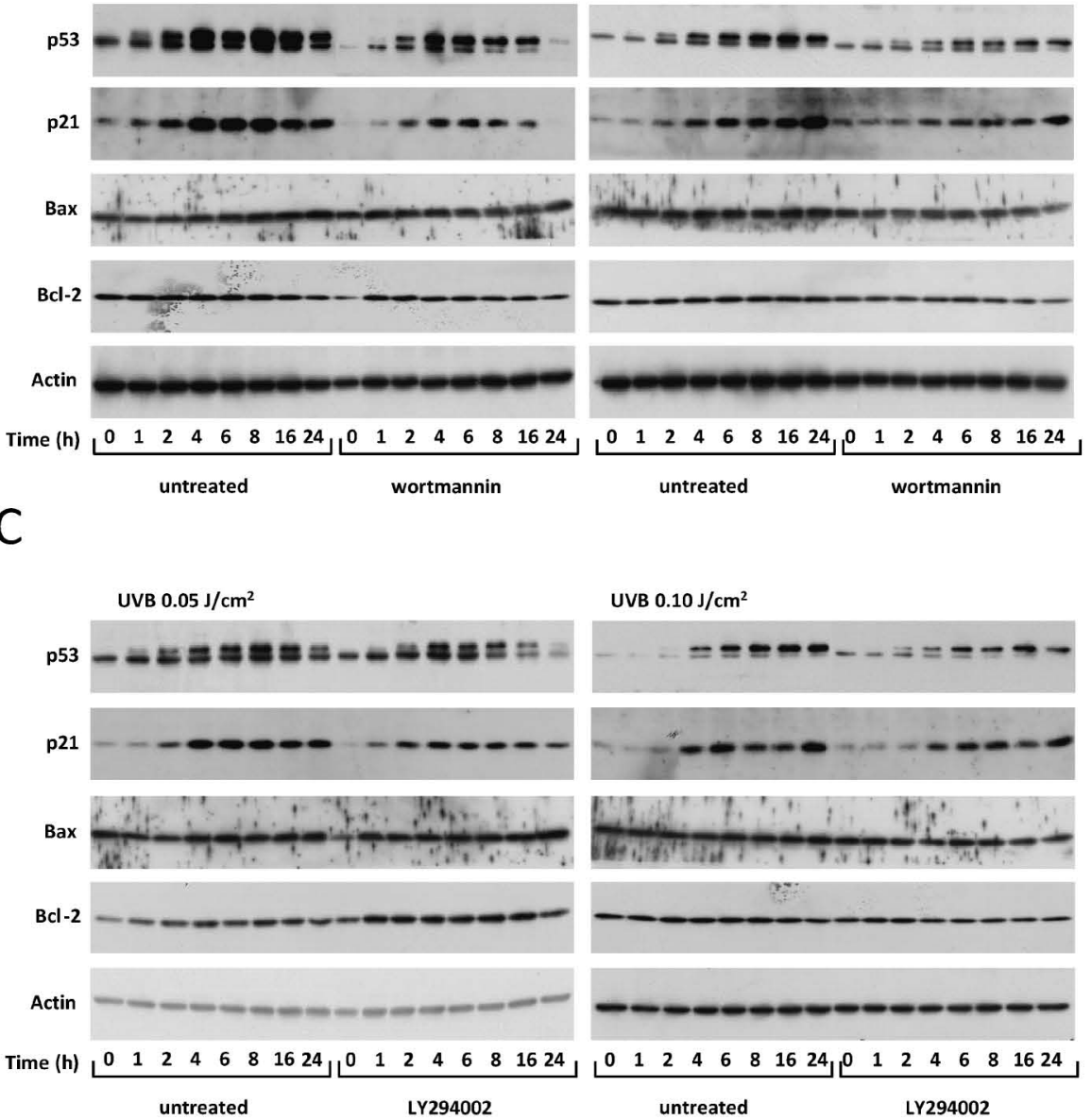

Fig. 2 Expression changes of p53, p21 and Bcl-2 family proteins after UVB exposure. Akt1-knocked down cells (A) and the cells treated with 100 $\mathrm{nM}$ wortmannin (B) and $10 \mu \mathrm{M}$ LY294002 (C) for $1 \mathrm{~h}$ were irradiated with UVB $\left(0.05\right.$ and $\left.0.1 \mathrm{~J} / \mathrm{cm}^{2}\right)$ and cultured for indicated time. They were harvested, and subjected to western blotting with anti-p53, anti-p21, anti-Bcl-2, anti-Bax and anti-Actin antibodies.

were fractionated to cytoplasm and nucleus. Nuclear import of p53 is essential for its normal function (23). p53 was accumulated in nucleus, not in cytoplasm (Fig. 4). In the case of Akt1 knockdown and treatment with inhibitors of PI3-kinase, p53 in nucleus decreased similar to in whole cells (Fig. 2), which was not due to the translocation to cytoplasm.

As the localization was not changed by Akt1 knock- 

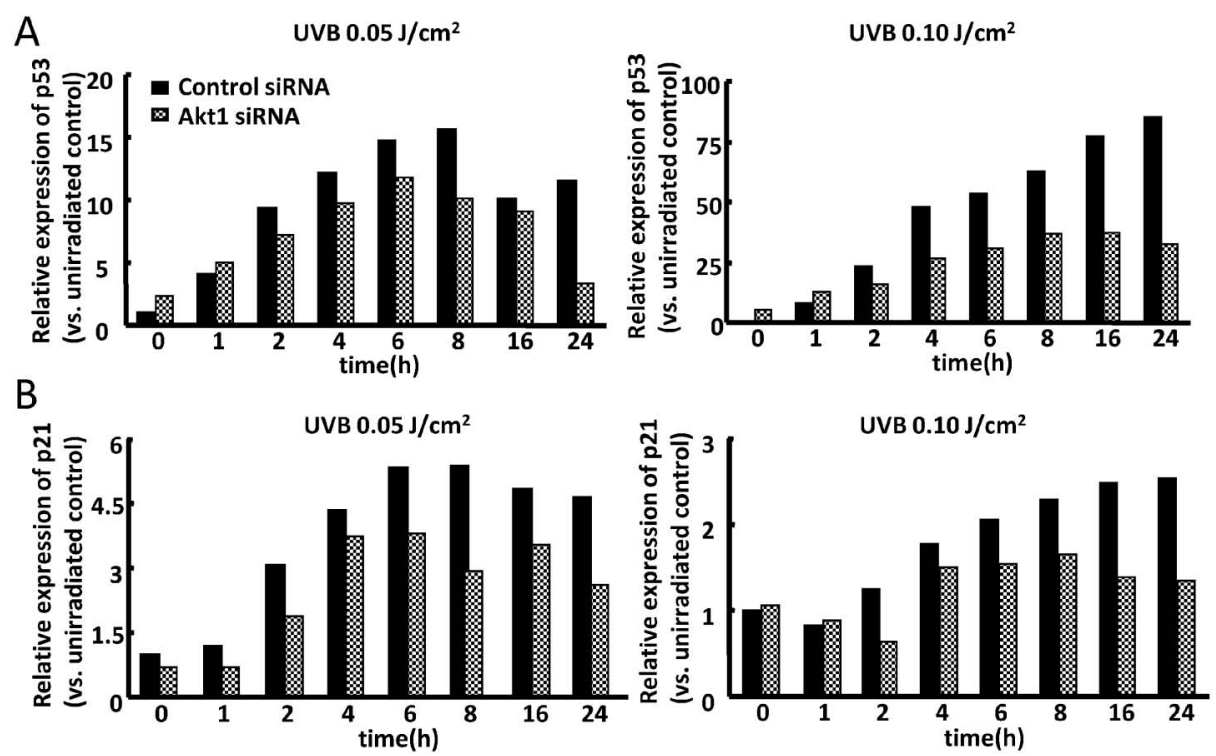

Fig. 3 Expression changes of p53 and p21 after UVB exposure. The bands of p53 (A) and p21 (B) in Fig. 2A were determined by NIH image (ver.1.61).
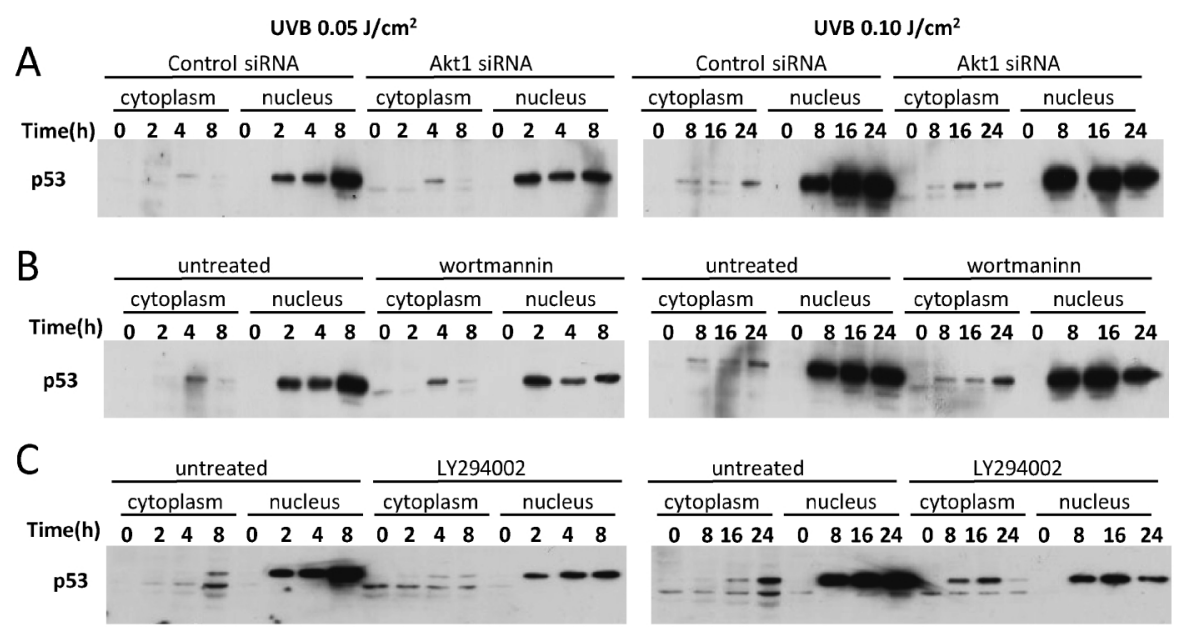

Fig. 4 Expression of p53 in subcellular fractions prepared from UVB irradiated cells. Akt1-knocked down cells (A) and the cells treated with 100 $\mathrm{nM}$ wortmannin (B) and $10 \mu \mathrm{M}$ LY294002 (C) for $1 \mathrm{~h}$ were irradiated with UVB $\left(0.05\right.$ and $\left.0.1 \mathrm{~J} / \mathrm{cm}^{2}\right)$ and cultured for indicated time. They were fractionated into nucleus and cytoplasmic fractions and subjected to western blotting with anti-p53 antibody.

down and treatment with PI3-kinase inhibitors, the attenuation of p53 was considered to be due to proteolysis. Proteasome inhibitor, MG132 was added to the cell culture immediately after UVB irradiation and timedependent expression of p53 was examined (Fig. 5). In the presence of MG132, p53 expression enhanced by UVB exposure was not degraded. Furthermore, attenuation of p53 by Akt1 knockdown and inhibitors of PI3kinase as shown in Fig. 2 also were not observed, suggesting that PI3-kinase/Akt would stabilize p53 after UVB irradiation via inhibition of proteolysis.

\section{Discussion}

Many researchers have been studied p53 phosphorylation, stabilization and degradation after UV irradiation. However, the detailed time-dependent change has not been reported. In this study, we demonstrated timedependent expressions of p53 and the related molecules, and contribution of PI3-kinase/Akt survival pathway involving induction of apoptosis.

UVB irradiation phosphorylated and stabilized p53 in a time-dependent manner (Fig. 2). The pattern was consistent with expression of $\mathrm{p} 21$. The patterns of induction of $\mathrm{p} 53$ and $\mathrm{p} 21$ were different dependent on UVB doses. In $0.05 \mathrm{~J} / \mathrm{cm}^{2}$ of UVB, p53 increased up to $8 \mathrm{~h}$ and 

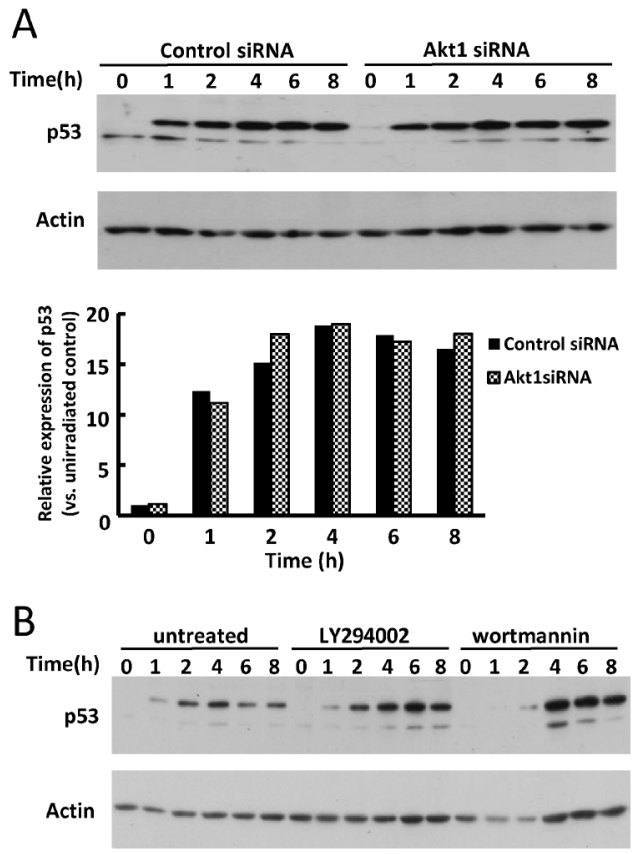

Fig. 5 Effect of proteasome inhibitor on the change of p53 expression after UVB irradiation. Akt1-knocked down cells (A) and the cells treated with $100 \mathrm{nM}$ wortmannin or $10 \mu \mathrm{M} \mathrm{LY} 294002$ (B) for $1 \mathrm{~h}$ were irradiated with UVB $\left(0.05 \mathrm{~J} / \mathrm{cm}^{2}\right)$ and cultured for indicated time in the presence of $10 \mu \mathrm{M}$ of MG132. The bands of p53 in Akt1-knocked down cells (A) were determined by NIH image (ver.1.61).

decreased. p21 increased up to $8 \mathrm{~h}$ and kept the expression. In $0.1 \mathrm{~J} / \mathrm{cm}^{2}$ of UVB, both $\mathrm{p} 53$ and $\mathrm{p} 21$ continuously increased up to $24 \mathrm{~h}$. The exact reason of the different patterns was not clarified; however, unrepaired DNA damages by exposure to excess doses of UVB might contribute to the continuous expression of these proteins.

The expressions of $\mathrm{p} 53$ and $\mathrm{p} 21$ after UVB irradiation were clearly attenuated by inhibitors of PI3-kinase and Akt1 knockdown. PI3-kinase/Akt is reported to facilitate the stabilization of $\mathrm{p} 53$ by reducing the interaction between negative regulator of $\mathrm{p} 53, \mathrm{Mdm} 2$ and p53 (24). In response to ionizing radiation, activation of Akt was resulted in hypophosphorylation of Mdm2 and incapability of mediating degradation of p53 (21). From our data that p53 was expressed at the same level in the presence of proteasome inhibitor even if Akt was knocked down (Fig. 5), PI3-kinase/Akt pathway would mediate proteasome-dependent degradation of p53 after UVB exposure.

Growth factors, IGF-1 and EGF, are well known to activate PI3-kinase/Akt pathway and suppress UV-induced cell death (15-17). Murray (25) showed that IGF-1 enhanced $\mathrm{p} 21$ expression, which inhibited UV-induced cell death. Downstream of p53, p21 is expressed and participates in DNA repair and apoptotic process (26). Suppression of p21 expression using PI3-kinase in- hibitors and Akt1 siRNA after UVB irradiation might contribute to the enhanced formation of apoptotic cells.

Although there are some reports that p53 induction after UV irradiation enhanced apoptosis $(4,5)$, the positive correlation of p53 and induction of apoptosis was not observed in this study. On the other hand, it was clear that PI3-kinase/Akt pathway mediated UVB-induced apoptosis. Ogawa et al. reported that the p53 family member p51/p63 inhibits UVB-induced apoptosis via PI3-kinase/Akt pathway (27). Furthermore, PI3kinase/Akt pathway can have multiple pro-survival effects, one of which is suppression of mitochondrialmediated apoptosis via phosphorylation and translocation of Bcl-2 family molecules (28). In this study, the expressions of pro- and anti-apoptotic Bcl-2 family were not so much changed after UVB irradiation. In addition, the expressions were kept even if PI3-kinase inhibitors and siRNA for Akt1 were treated. We checked it until $24 \mathrm{~h}$ after irradiation, but culture for longer time might be needed to observe the change. Bcl-2 family proteins were reported to be degraded 48 to $96 \mathrm{~h}$ after UV irradiation (29). Furthermore, only amounts of expressions of Bcl-2 family proteins were examined in this study, but phosphorylation and distribution on mitochondria membrane might be changed after UVB irradiation. UV irradiation translocated $B a x$ on mitochondria membrane and initiated apoptosis $(18,30,31)$.

In conclusion, the PI3-kinase/Akt pathway has important roles in apoptosis, and phosphorylation and stabilization of p53 after UVB irradiation. However, the pathway-mediated induction of apoptosis and change of expression of p53 did not have a positive correlation. Attenuation of UVB-induced apoptosis via activation of the pathway would have a role to suppress the formation of sunburn cells, leading to survival of mutated and transformed cells in skin. To understand the mechanism of UV-induced skin cancer, the pathway-mediated cellular responses would be required to examine in more detail.

\section{References}

1 Melnikova VO, Ananthaswamy HN. Cellular and molecular events leading to the development of skin cancer. Mutat Res. 2005; 571: 91-106.

2 Zuckerman V, Wolyniec K, Sionov RV, Haupt S, Haupt Y. Tumour suppression by p53: the importance of apoptosis and cellular senescence. J Pathol. 2009; 219: 3-15.

3 She QB, Chen N, Dong Z. ERKs and p38 kinase phosphorylate $\mathrm{p} 53$ protein at serine 15 in response to UV radiation. J Biol Chem. 2000; 275: 20444-9.

4 Ziegler A, Jonason AS, Leffell DJ, Simon JA, Sharma HW, Kimmelman J, Remington L, Jacks T, Brash DE. Sunburn and p53 in the onset of skin cancer. Nature. 1994; 372: 773-6.

5 Jiang W, Ananthaswamy HN, Muller HK, Kripke ML. 
p53 protects against skin cancer induction by UV-B radiation. Oncogene. 1999; 18: 4247-53.

6 Dhanalakshmi S, Agarwal C, Singh RP, Agarwal R. Silibinin up-regulates DNA-protein kinase-dependent p53 activation to enhance UVB-induced apoptosis in mouse epithelial JB6 cells. J Biol Chem. 2005; 280: 20375-83.

7 Chaturvedi V, Sitailo LA, Qin JZ, Bodner B, Denning MF, Curry J, Zhang W, Brash D, Nickoloff BJ. Knockdown of p53 levels in human keratinocytes accelerates Mcl-1 and Bcl-x(L) reduction thereby enhancing UV-light induced apoptosis. Oncogene. 2005; 24: 5299-312.

8 Clément V, Dunand-Sauthier I, Wiznerowicz M, Clarkson SG. UV-induced apoptosis in XPG-deficient fibroblasts involves activation of CD95 and caspases but not p53. DNA Repair. 2007; 6: 602-14.

9 Proietti De Santis L, Balajee AS, Lorenti Garcia C, Pepe G, Worboys AM, Palitti F. Inhibition of p53, p21 and Bax by pifithrin-alpha does not affect UV induced apoptotic response in CS-B cells. DNA Repair. 2003; 2: 891-900.

10 Ikehata H, Okuyama R, Ogawa E, Nakamura S, Usami A, Mori T, Tanaka K, Aiba S, Ono T. Influences of p53 deficiency on the apoptotic response, DNA damage removal and mutagenesis in UVB-exposed mouse skin. Mutagenesis. 2010; 25: 397-405.

11 Wan YS, Wang ZQ, Shao Y, Voorhees JJ, Fisher GJ. Ultraviolet irradiation activates PI 3-kinase/AKT survival pathway via EGF receptors in human skin in vivo. Int J Oncol. 2001; 18: 461-6.

12 Wang HQ, Quan T, He T, Franke TF, Voorhees JJ, Fisher GJ. Epidermal growth factor receptor-dependent, NFkappaB-independent activation of the phosphatidylinositol 3-kinase/Akt pathway inhibits ultraviolet irradiation-induced caspases-3, -8 , and -9 in human keratinocytes. J Biol Chem. 2003; 278: 45737-45.

13 Rosette C, Karin M. Ultraviolet light and osmotic stress: activation of the JNK cascade through multiple growth factor and cytokine receptors. Science. 1996; 274: 1194-7.

14 Datta SR, Dudek H, Tao X, Masters S, Fu H, Gotoh Y, Greenberg ME. Akt phosphorylation of BAD couples survival signals to the cell-intrinsic death machinery. Cell. 1997; 91: 231-41.

15 Majewski M, Nieborowska-Skorska M, Salomoni P, Slupianek A, Reiss K, Trotta R, Calabretta B, Skorski T. Activation of mitochondrial Raf-1 is involved in the antiapoptotic effects of Akt. Cancer Res. 1999; 59: 2815-9.

16 Kulik G, Klippel A, Weber MJ. Antiapoptotic signalling by the insulin-like growth factor I receptor, phosphatidylinositol 3-kinase, and Akt. Mol Cell Biol. 1997; 17: 1595-606.

17 Kuhn C, Hurwitz SA, Kumar MG, Cotton J, Spandau
DF. Activation of the insulin-like growth factor-1 receptor promotes the survival of human keratinocytes following ultraviolet B irradiation. Int J Cancer. 1999; 80: 431-8.

18 Decraene D, Agostinis P, Bouillon R, Degreef H, Garmyn M. Insulin-like growth factor-1-mediated AKT activation postpones the onset of ultraviolet B-induced apoptosis, providing more time for cyclobutane thymine dimer removal in primary human keratinocytes. J Biol Chem. 2002; 277: 32587-95.

19 Claerhout S, Decraene D, Van Laethem A, Van Kelst S, Agostinis P, Garmyn M. AKT delays the early-activated apoptotic pathway in UVB-irradiated keratinocytes via BAD translocation. J Invest Dermatol. 2007;127: 429-38.

20 Ibuki Y, Akaike M, Toyooka T, Goto R. Akt1-mediated intracellular oxidation after UVB irradiation suppresses apoptotic cell death induced by cell detachment and serum starvation. Photochem Photobiol. 2008; 84: 154-61.

21 Boehme KA, Kulikov R, Blattner C. p53 stabilization in response to DNA damage requires Akt/PKB and DNAPK. Proc Natl Acad Sci USA. 2008; 105: 7785-90.

22 Ibuki Y, Goto R. Antiapoptotic effects induced by different wavelengths of ultraviolet light. Photochem Photobiol. 2002; 75: 495-502.

23 Liang SH, Clarke MF. Regulation of p53 localization. Eur J Biochem. 2001; 268: 2779-83.

24 Lavin MF, Gueven N. The complexity of p53 stabilization and activation. Cell Death Differ. 2006; 13: 941-50.

25 Murray SA, Zheng H, Gu L, Jim Xiao ZX. IGF-1 activates p21 to inhibit UV-induced cell death. Oncogene. 2003; 22: 1703-11.

26 O'Reilly MA. Redox activation of p21Cip1/WAF1/Sdi1: a multifunctional regulator of cell survival and death. Antioxid Redox Signal. 2005; 7: 108-18.

27 Ogawa E, Okuyama R, Ikawa S, Nagoshi H, Egawa T, Kurihara A, Yabuki M, Tagami H, Obinata M, Aiba S. p51/p63 Inhibits ultraviolet B-induced apoptosis via Akt activation. Oncogene. 2008; 27 : 848-56.

28 Duronio V. The life of a cell: apoptosis regulation by the PI3K/PKB pathway. Biochem J. 2008; 415: 333-44.

29 Batista LF, Roos WP, Kaina B, Menck CF. p53 mutant human glioma cells are sensitive to UV-C-induced apoptosis due to impaired cyclobutane pyrimidine dimer removal. Mol Cancer Res. 2009; 7: 237-46.

30 Bivik CA, Larsson PK, Kagedal KM, Rosdahl IK, Ollinger KM. UVA/B-induced apoptosis in human melanocytes involves translocation of cathepsins and Bcl-2 family members. J Invest Dermatol. 2006; 126:1119-27.

31 Wu Y, Xing D, Liu L, Gao B. Regulation of Bax activation and apoptotic response to UV irradiation by p53 transcription-dependent and -independent pathways. Cancer Lett. 2008; 271: 231-9. 